\title{
Investigative Study of Partial Replacement of Cement with Bio-Cement, Fly Ash and Natural Pozzolans
}

\section{Dr.Sarvesh PS Rajput}

Assistant Professor, Department of Civil Engineering, Maulana Azad National Institute of Technology, Bhopal (MP)

Article History: Received: 11 January 2021; Accepted: 27 February 2021; Published online: 5 April 2021

\begin{abstract}
:
Concrete is usually a combination of cement, coarse particles (aggregates and Sand) and water. It is used to design and improve the infrastructures.It is used to design and improve the infrastructures. Concrete has many advantages and disadvantage. The main property that is characteristic to a concrete's workability is its compressive strength. Only through this single test, one can judge if cementing has been done appropriately. Possible advancements for development include the use of non-traditional and creative materials, and the reuse of waste materials with a specific end goal to replenish the absence of specific assets and to discover alternative ways to monitor the Earth..This investigation concentrate on Compressive strength, flexural and split tensile strength of Conventional Concrete (CC) and Class $\mathrm{C}$ fly ash remains with biocement and natural pozzolans to consider the impact of bio-concrete with blend extents of $0 \%, 0.25 \%, 0.5 \%, 1 \%$ and $1.5 \%$ on quality properties. Moreover, effective self-healing usually occurred due to the use of polymers, microorganism and additional cementing material. It is the key issue to find out the self-healing efficiency's effect to sealing the crack width successfully. And good resistance was observed during the bacterial chemical process against the freeze and thaw attacks.
\end{abstract}

Keywords: Natural pozzolans, Compressive strength, Bio-cement, Calcium carbonate, Split tensile strength,

\section{Introduction}

Concrete is usually a combination of cement, coarse particles (aggregates and Sand) and water. It is used to design and improve the infrastructures. Concrete has many advantages and disadvantages. Due to the strength, durability and permeability of concrete, its demand is increasing year by year [1]. Its demand also increases due to availability, low price and possibility to make the desired size and shape. Concrete has an age of about 50 year normally, after that because of the effect of weather (effect of sunlight and rain) it forms cracks. Ecological connection during which the decay of solid happens through progressive patterns of expansion, breaking, loss of mass and expanded water penetrability.

It is impossible to prevent the cracks formation. These cracks allow different chemicals to entered or penetrate in its structure. In the result of cracks, it loses its durability. Cracks are seen in both plastic and hardened conditions. In plastic state, cracks are due to shrinkage, settlement and rapid loss of water while in hardened state, it is due to weather effects, thermal effect and absence of water content (dryness) and many other reasons $[2,3]$.

Cracks thus formed at the beginning are quite superficial, perhaps not more than a fraction of millimetre deep and do not cause structural problems [4]. With the exception of opening up later and passage of aggressive agents loose structure integrity by corrosion of steel, carbonation, delayed ettringite formation and finally failure of the structure. An environmental friendly solution to overcome this problem is by controlling or to minimize pores at initial stage of conversion of ettringite to $\mathrm{C}-\mathrm{S}-\mathrm{H}$ gel itself and thus forming dense and water-tight concrete [5].

\section{Bio-cement}

The Microbial induced Calcium Carbonate Percipitation (MICCP) mechanism is used in the formation of the Bio- Cement, where calcium ions and urea in presence of water give precipitates of calcium carbonate $(\mathrm{CaCO} 3)$ produced by microbial activity. Complete equation of formation of $\mathrm{CaCO} 3$ ppt. is given below:

$$
\mathrm{CO}(\mathrm{NH} 2) 2+\mathrm{Ca} 2++2 \mathrm{H} 20 \rightarrow 2 \mathrm{NH} 4++\mathrm{CaCO} 3 \text { (cal. carbonate ppt.) }
$$

Due to the ability to form an alkaline environment through physical activities the microorganism have an important role in the carbonate precipitate. Biologically induced mineral precipitation resulting from metabolic activity performs animportant role to improve the behaviour of concrete material [6].

The concrete based on Bacteria is thought to be solution with the name of self-healing concrete. But in this concept cracks will be filled with Micro biologically induced Calcium Carbonate precipitate (MICCP) after formation of cracks. But making concrete such as without any cracks for life time is the concept of Bio-concrete. This is made by augmenting OPC with Bio-cement. 


\section{Literature Review}

Van Tittelboom et al. [7] reported that supplementary material is used to improve the micro cracks in concrete by self-healing effect. This supplementary concrete material has two advantages, decreases the amount of cement material and increases the repairing efficiency of cracks.

Pang et al. [8] include immobilized bacterial culture inside the solid framework utilizing polyurethane. Consequently, their life range was reached out with the inevitable diminishing of enzymatic action (Calcite precipitation). Be that as it may, this, nonetheless, settles the enzymatic action for a significant stretch of time. Wang et al. [5] likewise confirmed a similar process, wherein, they reported $60 \%$ recovery in compression strength of concrete because of immobilization of bacterial species. Besides, Wang et al. [6] have immobilized bacterial spores in an encapsulation of hydrogel prior to blending them in with the concrete. It was observed that cracks having $0.5 \mathrm{~mm}$ width were totally filled. The water retention was additionally decreased by $68 \%$. Irwan and Othman [7] brought ureolytic microscopic organisms into the concrete lattice. Their physical activities caused precipitation of calcium carbonate in the cracked areas with the probable filling of the cracks. Moreover, upon immobilization, an improved execution was noted particularly at later ages [8]. Moreover, utilization of MICCP through bio-mineralization measure has been considered as a novel technique in improving durability and compressive strength of concrete. Further, this bio-based treatment had been widely focused to improve the general presentation of concrete at lab scale tests $[9,10]$.

\section{Methodology}

The concrete mix was dissolved in the slump molds and packed appropriately to remove the voids. Moreover, the top surface of these specimens was made even and smooth. Following 24 hours the molds were extracted and were placed in limewater for the curing purpose. It is finished by putting concrete glue and spreading easily all in all zone of example. The examples were tested on the pressure testing machines on 7,14 and 28 days of the relieving respectively. Loads were applied progressively until the sampled molds fails compressive pressure tests.

\subsection{Materials and Method}

\section{Bio-cement}

It is the combination of 5\% Bacillus Pasteurii and 95\% adjuvants like urease and lactose enzyme. This forms MICCP precipitate. Precipitate which forms fills the gel pores developed in the formation of C-S-H gel strengthens transition zone by forming precipitate around the aggregate.

To inject to the sand core in pipe column the solution of urea, calcium and bacteria solution immediately mixed and put in the pressurized vessel, until the sand core fully saturated. It took 2 hours in completion of Bio Cementation reaction after this completion of process the Bio- Cement has been dried at a temperature of $60^{\circ} \mathrm{C}$.

\section{Fly ash}

As per ASTM-C618, Class C fly remains obtained from Rayalaseema Thermal Power Plant (RTPP), Muddanur, Andhra Pradesh was used.

\section{Natural Pozzolans:}

For getting the cementitious material the Natural Pozzolans put into use that controls the risen temperature in the mass concrete, they are also use to improve the resistance for sulphate attacks and this is among the first materials that were found helpful in mitigation of the alkali silica reaction. Calcined clay was used in the current concrete preparation.

The different materials that is used as concrete preparation mixture are represented in Table 1.

Table 1: Concrete mix preparation

\begin{tabular}{|l|c|}
\hline Materials & Proportion (\%) \\
\hline OPC & 17 \\
\hline Sand & 4 \\
\hline
\end{tabular}




\begin{tabular}{|l|c|}
\hline Aggregates & 39 \\
\hline $\mathrm{W} / \mathrm{c}$ & 0.6 \\
\hline
\end{tabular}

\subsection{Immobilization of Bacterial spores:}

The formation of the $\mathrm{Ca}(\mathrm{OH}) 2$, characterized the young concrete matrix with the higher $\mathrm{pH}$ values, that is quantitatively the most important hydration product after the Calcium- Silica-Hydrate. Therefore the bacterial spores that use to place into the concrete should not only have the capability to resist the mechanical stresses but also have ability to face the high $\mathrm{pH}$ environment for long periods

Therefore, the bacterial spores were immobilized using hydrogel prior to concrete preparation process.

\subsection{Experiments}

The concrete slumps were tested for compressive and splitting tensile strengths (IS5816(1999), modulus of rupture and elasticity according to IS:516(1959).

\section{Compressive strength}

The main property that is characteristic to a concrete's workability is its compressive strength. Only through this single test, one can judge if cementing has been done appropriately.

\section{Microscopic Evaluation}

These tests are either for characterizing or identifying the deposited layer present within the concrete after self-healing mechanism that is consists of (XRD) X-ray diffraction and (SEM)Scanning electron microscope.

\section{Results}

Calcined clay and fly ash were found to improve the functionality of concrete of the slupms. Moreover, fly ash and Calcined clay, etc. contribute to the strength gain of concrete. Various experimental outputs are represented in Figures 2-4.

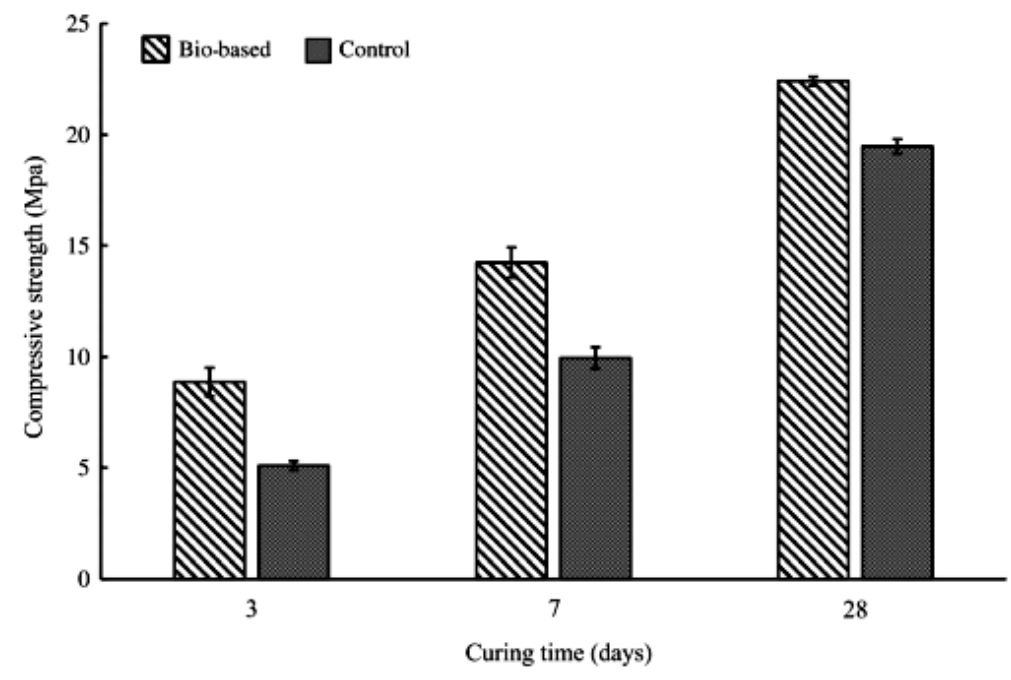

Figure 2: Compressive strength of concrete mixes

The outcomes from XRD investigation are represented in Fig. 3. The information emphatically proposed that incorporation of microorganisms can support calcium carbonate precipitation. For the reactive $\mathrm{CaCO} 3$ precipitates related with the microbial activity and growth, the very peak at nearly $30^{\circ} 2 \theta$ recommends the existence of exceptionally high crystalline structures of the calcium carbonate $\left(\mathrm{CaCo}_{3}\right)$ mineral calcite[11]. The concrete specimens acquired from the parallel control analysis performed with the agar control without bioconcrete were for the most part made out of exceptionally crystalline structures of calcite and quartz. Carbon dioxide is discharged as a result of the carbonation in presence of water within the concrete pores and while reacting with $\left(\mathrm{Ca}(\mathrm{OH})_{2}\right)$. 


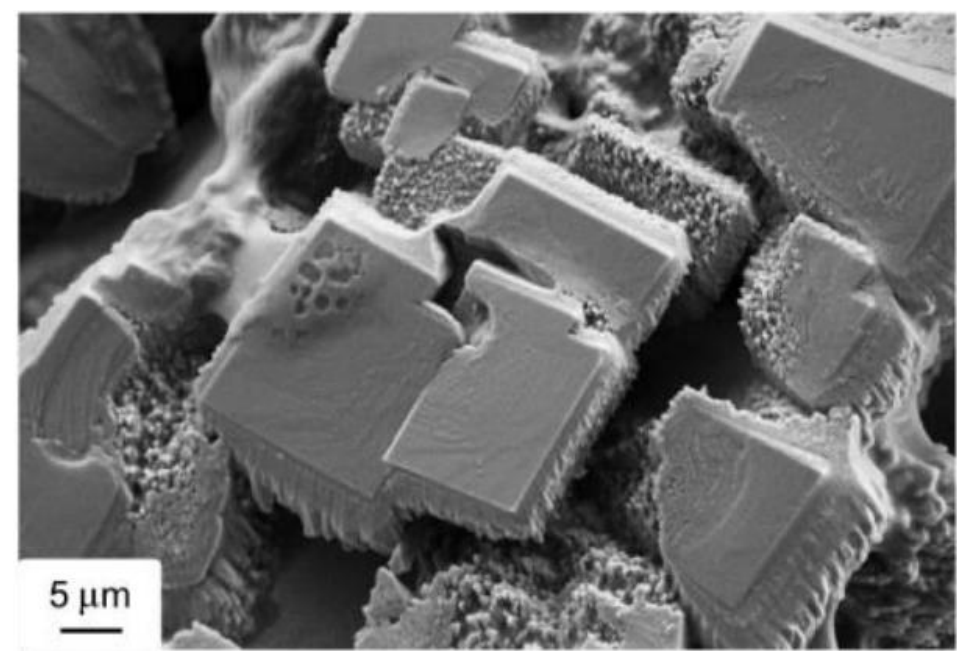

Figure 3: Calcite crystals in sample using SEM

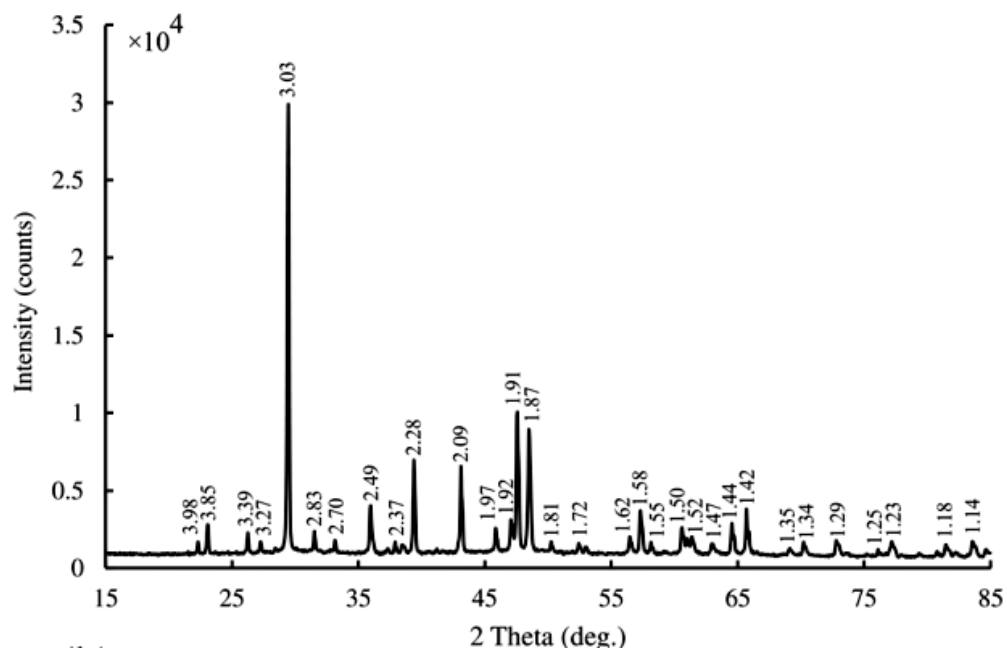

Figure 4: XRD graph of the sample

\section{Conclusion}

The results of the current study suggests the partial replacement of cement with fly ash and natural pozzolans along with incorporation of immobilized microbial spores enhances the compressive strength and of the modulus of elasticity. XRD analysis and SEM images confirmed that the crystalline structures precipitated on the concrete's micro-structure were actually composed of calcium carbonate. Moreover, We observed in bacterial chemical process that the resistance was quite good against the freeze and thaw attacks. The outcomes of the present study suggest that there is a potential of incorporating microbial spores to be used in bio-cement based concrete mix as self-healing concrete for the development of sustainable infrastructures.

\section{Future Recommendations}

More experimental work should be done to find efficiency of Bio-cement based concrete mixture in natural bonding formed by C-S-H gel. Additionally, long term efficiency of bio minerals and natural admixtures should be investigated. 


\section{References}

[1] Samani, A.K. and M.M. Attard. Lateral strain model for concrete under compression. ACI Structural Journal, 2014;111(2):441-451.

[2] Ramesh Babu TS, Neeraja D. Effect of natural admixture on fresh properties and compressive strength of class c fly ash blended concrete, Asian Journal of Civil Engineering (BHRC). 2016;3(17):373-84.

[3] Ahn, T.H., D.J. Kim and S.H. Kang. Crack self-healing behavior of high performance fiber reinforced cement composites under various environmental conditions. Earth Space. 2012:635-640.

[4] Bang, S.S., Galinat, J.K. Ramakrishnan, V. Calcite precipitation induced bypolyurethane-immobilized Bacillus pasteurii, Enzyme Microb. Technol. 2001;28(4-5):404-409.

[5] A.Kumar,PS.Rathore,A.Dubey,R,Agrawal (2020)“Low-Power Traffic Aware Emergency based Narrowband Protocol with holistic Ultra Wideband WBAN approach in biomedical application, Ad Hoc \& Sensor Wireless Networks, ISSN: 1552-0633.

[6] Wang, J.Y. Soens, H. Verstraete, W. De, B.N. Self-healing concrete by use of micro-encapsulated bacterial spores, Cem. Concr. Res. 56 (2014) 139-152.

[7] Chahal, N. Siddique, R. Rajor, A. Influence of bacteria on the compressive strength, water absorption and rapid chloride permeability of fly ash concrete, Constr. Build. Mater. 2012;28(1):351-356.

[8] Pang, B. Zhogui, Z. Pengkun, H. Peng, D. Lina, Z. Hongxin, X. Autogenous and engineered healing mechanisms of carbonated steel slag aggregate in concrete, Constr. Build. Mater. 2016;107:191-202.

[9] Bekas, D.G. Tsirka, K. Baltzis, D. Paipetis, A.S. Self-healing materials: a review of advances in materials, evaluation, characterization and monitoring techniques, Compos. B Eng. 2015;87:92-119.

[10] A.Dubey,A.Kumar,R.Agrawal. An efficient ACO-PSO based framework for data classification and preprocessing in big data", Evolutionary Intelligence Springer Electronic ISSN 1864-5917,Print ISSN 18645909.

[11]Talaiekhozan, A., A keyvanfar, A Shafaghat, R Andalib, M.Z.Majid, M.A Fulazzaky, M.Z Roshi, C.T Lee, M.W Hussin, N. Hamzah, N.F Marwar and H.I Haider. A Review Of Self-Healing Concrete Research Development. Journal Of Environmental Treatment Techniques, 2013;2(1):1-11. 